\title{
Problem of chronic endometritis in cows and ways to solve it
}

\author{
Sergey Shabunin ${ }^{1}$, Ivan $_{\text {Bondarev }}{ }^{1}$, Vitaly Mikhalev ${ }^{1}$, Igor Tolkachev $^{1}$, and Anatoly Stekolnikov ${ }^{2}$ \\ ${ }^{1}$ All-Russian Veterinary Research Institute of Pathology, Pharmacology and Therapy, 394087 Voronezh, Russia \\ ${ }^{2}$ Saint-Petersburg State Academy of Veterinary Medicine, 196084 St. Peterburg, Russia
}

\begin{abstract}
Chronic endometritis is diagnosed on average in $18.1 \%$ of infertile cows. With chronic endometritis, the uterus has a pronounced cavity of $18.4 \pm 0.9 \mathrm{~mm}(11-35 \mathrm{~mm})$, while the wall thickness of the uterus is on average $8.7 \pm 0.37 \mathrm{~mm}$. Morphometrically chronic endometritis is characterized by a decrease in the fraction of functionally active elements of the endometrium (integument epithelium, uterine glands, blood vessels) to $12.17 \%$. In the development of chronic endometritis, cows compared with clinically healthy animals showed an increase in leukocyte content by $12.2 \%$, monocytes by 2.5 times, creatinine by $29.7 \%$, average molecular peptides by $25.0 \%$, and endogenous intoxication index by $25.4 \%$, circulating immune complexes by $38.5 \%$, with a decrease in the bactericidal and lysozyme activity of blood serum, respectively by 10.7 and $12.9 \%$ and phagocytic activity of leukocytes by $12.4 \%$. The effectiveness of the application of the developed method for the treatment of chronic endometritis, involving the use of aminoseleton five times with a 72-hour interval at a dose of 30, 35, 40, 45 and $50 \mathrm{ml}$, magestrofan on the 1st and 13th days at a dose of $2 \mathrm{ml}$, uterotone on 3rd, 4th and 5th days at a dose of $10 \mathrm{ml}$ and intrauterine administration of primalact on $1 \mathrm{st}-3 \mathrm{rd}$ days at a dose of $20 \mathrm{ml}$, is $88.0 \%$. Recovery of animals after the treatment is accompanied by a decrease in the inflammatory response, endogenous intoxication, normalization of liver and kidneys, an increase in overall non-specific resistance and a decrease in uterine microbial contamination.
\end{abstract}

\section{Introduction}

At the present stage of development of dairy animal husbandry, one of the constraining factors is the gynecological diseases of cows, which include chronic endometritis registered in $15.0-67.0 \%$ of infertile animals [1,2].

In most cows with chronic endometritis, the uterine cavity is populated by a variety of microflora, which for a long time can support the inflammatory process and prevents the fertilization of animals $[3,4]$.

In recent years, highly productive cows have increased the frequency of inflammatory processes caused by opportunistic microorganisms. First of all, this is due to the introduction of broad-spectrum antibiotics into veterinary practice, which led to noticeable disturbances in the environmental relationships between a macroorganism and its microflora $[5,6]$.

The tactics of therapeutic effects in chronic endometritis in cows is aimed, first of all, at suppressing the vital functions of microorganisms in the uterine cavity and completely eliminating pathological changes in the endometrium. However, the nonspecific use of chemotherapeutic agents in the treatment of acute postpartum endometritis leads to an increase in the drug resistance of microorganisms, weakening of protective mechanisms, spontaneous mutations, causing the appearance of genetically resistant populations, which complicates the treatment, and chemotherapy becomes a link of etiopathogenesis of chronic endometritis of cows $[7,8]$.

Untimely and ineffective treatment of chronic endometritis in cows leads to impaired reproductive function, decreased milk productivity and premature culling $[9,10]$.

In this regard, the study of the clinical and pathogenetic features of the development of chronic endometritis in dairy cows and the development of methods for its pharmacotherapy are high on the agenda and require detailed study.

\section{Materials and methods}

\subsection{Objects of study}

The objects of the study are clinically healthy cows and those diseased by chronic endometritis.

\subsection{The study of clinical, ultrasound and morphometric diagnostic criteria}

The criteria for the diagnosis of chronic endometritis in infertile cows were studied using an Easi-Scan ultrasound scanner equipped with a linear sensor with a frequency of $7.5 \mathrm{MHz}$. According to the results of the studies, animals were divided into two groups: clinically healthy and those with chronic endometritis.

* Corresponding author: mikhalevvit@yandex.ru 
Morphometric studies of histological material were performed according to G.G. Avtandilov [11].

\subsection{Morphological, biochemical, immunological studies of blood of cows}

Blood samples were taken from cows with chronic endometritis and clinically healthy animals for morphological, biochemical and immunological studies. A hemomorphological blood test was performed on an ABX Micros 60 hematology analyzer, and biochemical studies were carried out in accordance with the Methodological Guidelines for the Diagnosis, Treatment, and Prevention of Metabolic Disorders in Productive Animals [12]. Immunological indicators: serum bactericidal activity (SBA), serum lysozyme activity (SLA), total immunoglobulins, circulating immune complexes, leukocyte phagocytic rate (LPR) were determined using standard and unified methods in accordance with the Methodological Recommendations for the Assessment and Correction of the Immune Status of Animals [13].

\subsection{Determining the effectiveness of a comprehensive method for the treatment of chronic endometritis in cows}

The effectiveness of the developed method for the treatment of chronic endometritis was studied in 46 sick cows. The animals of the first group $(n=25)$ on the 1 st, 4th, 7th, 10th and 13th days were injected subcutaneously with aminoseleton in increasing doses: $30,35,40,45$ and $50 \mathrm{ml}$ and starting from the third day of treatment. Daily during 2-3 days an antimicrobial preparation primalact in a dose of $20 \mathrm{ml}$ was administered in the uterine cavity. In the second group $(\mathrm{n}=21)$ in the 1st, 5th and 9th treatment days the animals were subcutaneously injected denatured emulsified placenta at a dose of $25 \mathrm{ml}$, while intrauterine injection involved metricur according to the instructions for its use. In addition, on the 1st and 13th day of treatment, the animals of both groups were injected intramuscularly with magestro-fan at a dose of $2 \mathrm{ml}$ and tetrahydrovit at a dose of $6 \mathrm{ml}$, while at 3, 4, 5 days, uterotone was injected intramuscularly at a dose of $10 \mathrm{ml}$. Assessment of therapeutic efficacy was carried out according to the number of recovered animals, the number of intrauterine administrations of antimicrobial drugs, the percentage of fertilized cows, the rate of fertilization and the period from the start of treatment to fertilization. From 5 animals from each group, blood samples were taken for laboratory tests before and after treatment. The experimental data were processed using the Statistica 8.0 applied statistical program (StatSoft Inc., USA).

\section{Results and discussion}

Studies on the prevalence of chronic endometritis were carried out on 736 infertile cows in 5 farms of the Voronezh region. It was found that chronic endometritis was diagnosed in 256 infertile animals, or in $18.1 \%$ of those examined.

Clinical-echographic studies have shown that chronic endometritis is characterized by an increase in the size of the uterus by $1.5-2.0$ times, a weakly expressed response to massage, and an elastic consistency. The horns of the uterus in chronic endometritis hang over the edge of the pubic symphysis into the abdominal cavity. With chronic endometritis, catarrhal-purulent, purulent-catarrhal exudate, echographically represented as single echopositive inclusions, is noted. The uterus has a pronounced cavity: $18.4 \pm 0.9 \mathrm{~mm}(11-35 \mathrm{~mm})$, the thickness of the uterine wall in chronic endometritis is on average $8.7 \pm 0.37 \mathrm{~mm}$.

In chronic endometritis, in $36.6 \%$ of cases, functionally active cyclic yellow bodies with a size of $13.9 \pm 0.9 \mathrm{~mm}$ are diagnosed in the ovaries. In most cases $(48.7 \%)$, the course of chronic endometritis occurs against the background of ovarian hypofunction, in $11.0 \%$ luteal cysts with a diameter of $29.1 \pm 1.3 \mathrm{~mm}$ are diagnosed.

The degree of microbial contamination of cervicalvaginal mucus in chronic endometritis was $3913.7 \pm 204.8$ $\mathrm{CFU} / \mathrm{ml}$, which is $19.9 \%(\mathrm{P}<0.05)$ less compared with the pyometra and 3.37-3.98 times more than with pathologies of the uterus of a functional nature (chronic uterine subinvolution, glandular cystic hyperplasia of the endometrium). With the development of chronic endometritis, exudate in $66.6 \%$ is contaminated with enterobacteria. The species composition of microflora isolated from the uterine content of patients with chronic endometritis of cows is represented by E. coli $(66.7 \%$ of cases), Staph. aureus $(25.0 \%)$, Ent. faecalis $(25.0 \%)$, Ent. faecium $(25.0 \%)$, Staph. epidermidis $(8.3 \%)$, yeast-like fungi $(41.7 \%)$, Asp. fumigatus $(33.3 \%)$. At the same time, microflora was isolated in the form of monoculture in $41.7 \%$ of cases and in the form of associations in $58.3 \%$ of cases. The content of neutrophilic leukocytes in the cervical-vaginal mucus of cows with chronic endometritis is $14.1 \pm 0.91 \%$, which is $1.38-2.2$ times higher $(\mathrm{P}<0.01)$ than in functional disorders, confirming the presence of an inflammatory process in the uterus.

In the structure of the endometrium of cows with chronic endometritis, the fraction of integumentary epithelium is $2.12 \pm 0.21 \%$, uterine glands $5.21 \pm 0.33 \%$, blood vessels $4.84 \pm 0.29 \%$, and endometrial stroma $87.83 \pm 6.1 \%$, while in the case of uterine pathologies of functional nature the figures are 3.21-5.71 \%, 6.72-28.64 \%, $7.45-12.31 \%$ and $53.34-79.24 \%$, respectively. Thus, in the case of chronic endometritis, the fraction of functionally active elements of the endometrium decreases to $12.17 \%$. The height of the integumentary epithelium cells in the case of chronic endometritis is $17.9 \pm 1.48 \mu \mathrm{m}$, which is $13.5-20.1 \%(\mathrm{P}<0.05)$ less in comparison with chronic pathologies of the uterus of an inflammatory nature, the thickness of the endometrium is $297.8 \pm 21.6 \mu \mathrm{m}$, and the height of the epithelial cells is of the uterine glands is $11.8 \pm 0.88 \mu \mathrm{m}$, which is less by $13.9-34.9 \%(\mathrm{P}<0.05-0.01)$ and $15.5-30.2 \%(\mathrm{P}<0.05)$, respectively. The volume of epithelial epithelium in the case of chronic endometritis is $472.9 \pm 33.8 \mu \mathrm{m}^{3}$, and the 
volume of their nuclei is $156.8 \pm 12.4 \mu \mathrm{m}^{3}$, which is respectively less by 36.6-47.2 ( $\mathrm{P}<0.001)$ and $20.7-34.1 \%$ $(\mathrm{P}<0.01)$ compared with chronic diseases of the uterus of a functional nature, and the volume of uterine gland epithelial cells and their nuclei is $357.8 \pm 29.6 \mu \mathrm{m}^{3}$ and $119.5 \pm 9.1 \mu^{3}$, which is respectively less by $23.7-46.4$ $(\mathrm{P}<0.01-0.001)$ and 19.6-36.8\% $(\mathrm{P}<0.01)$. Thus, in chronic endometritis, a decrease in the volume of epithelial cells of the integumentary epithelium and uterine glands is noted, which indicates the development of dystrophic processes.

The results of morphometric studies are additional markers for the diagnosis of chronic endometritis in dairy cows, which also include indicators of morphological and biochemical status (Table 1).

Table 1. Morphological and biochemical blood parameters of cows with chronic endometritis

\begin{tabular}{|c|c|c|}
\hline Indicators & $\begin{array}{c}\text { Clinically } \\
\text { healthy, } n=5\end{array}$ & $\begin{array}{c}\text { Chronic } \\
\text { endometritis, } n=5\end{array}$ \\
\hline Leukocytes [109/1] & $8.2 \pm 0.37$ & $9.2 \pm 0.19^{*}$ \\
\hline Eosinophils [\%] & $2.8 \pm 0.21$ & $3.0 \pm 0.14$ \\
\hline \multicolumn{3}{|l|}{ Neutrophils [\%] } \\
\hline stab & $2.8 \pm 0.13$ & $4.7 \pm 0.14^{* * *}$ \\
\hline segmented & $43.4 \pm 3.0$ & $40.7 \pm 3.1$ \\
\hline Monocytes [\%] & $2.8 \pm 0.45$ & $7.0 \pm 0.34^{* * *}$ \\
\hline Lymphocytes [\%] & $48.5 \pm 2.4$ & $44.6 \pm 3.3$ \\
\hline Total protein [g/l] & $78.1 \pm 4.2$ & $77.4 \pm 4.7$ \\
\hline \begin{tabular}{|l|} 
Albumins [\%] \\
\end{tabular} & $40.7 \pm 2.9$ & $35.5 \pm 2.1^{*}$ \\
\hline$\alpha$-globulins [\%] & $11.6 \pm 0.6$ & $11.9 \pm 0.4$ \\
\hline$\beta$-globulins [\%] & $21.3 \pm 0.6$ & $23.7 \pm 0.8^{*}$ \\
\hline$\gamma$-globulins [\%] & $26.4 \pm 1.6$ & $28.9 \pm 1.8$ \\
\hline Creatinine $[\mu \mathrm{M} / \mathrm{L}]$ & $67.4 \pm 4.1$ & $87.4 \pm 5.7^{*}$ \\
\hline AST [units/l] & $62.7 \pm 4.1$ & $90.7 \pm 4.8^{* * *}$ \\
\hline ALT [units/l] & $15.4 \pm 1.1$ & $22.7 \pm 1.2^{* *}$ \\
\hline ALP [units/l] & $55.4 \pm 3.1$ & $70.4 \pm 5.1^{* *}$ \\
\hline GTP [units/l] & $13.7 \pm 1.1$ & $21.7 \pm 1.4^{* *}$ \\
\hline MMP [a.u.] & $0.7 \pm 0.01$ & $1.0 \pm 0.02^{* * * *}$ \\
\hline MDA $[\mu \mathrm{M} / \mathrm{L}]$ & $2.21 \pm 0.19$ & $2.54 \pm 0.11^{*}$ \\
\hline Catalase $\mu \mathrm{M}_{\mathrm{H} 2 \mathrm{O} 2} / \mu \mathrm{min}$ & $52.8 \pm 3.4$ & $40.8 \pm 2.4^{*}$ \\
\hline $\mathrm{GPx}[\mu \mathrm{M} / \mathrm{l} \cdot \mathrm{min}]$ & $16.8 \pm 0.8$ & $13.4 \pm 0.8^{*}$ \\
\hline IEI & $20.5 \pm 0.5$ & $25.7 \pm 1.2^{* *}$ \\
\hline $\mathrm{NO}_{\mathrm{x}}[\mu \mathrm{M} / \mathrm{l}]$ & $36.5 \pm 1.2$ & $40.1 \pm 2.8$ \\
\hline Vitamin $\mathrm{A}[\mu \mathrm{M} / 1]$ & $1.51 \pm 0.07$ & $1.22 \pm 0.05^{* *}$ \\
\hline Vitamin $\mathrm{E}[\mu \mathrm{M} / 1]$ & $18.8 \pm 1.4$ & $15.6 \pm 0.9$ \\
\hline Vitamin $\mathrm{C}[\mu \mathrm{M} / \mathrm{l}]$ & $20.6 \pm 1.7$ & $18.4 \pm 1.2$ \\
\hline Carotene $[\mu \mathrm{M} / \mathrm{L}]$ & $15.4 \pm 1.3$ & $12.7 \pm 1.0$ \\
\hline Selenium $[\mu \mathrm{M} / \mathrm{L}]$ & $1.51 \pm 0.08$ & $1.22 \pm 0.07^{*}$ \\
\hline $\begin{array}{l}\text { Total } \\
\text { immunoglobulins }[\mathrm{g} / \mathrm{l}]\end{array}$ & $22.9 \pm 2.2$ & $19.4 \pm 1.3$ \\
\hline CIC $[\mathrm{g} / \mathrm{l}]$ & $0.13 \pm 0.02$ & $0.18 \pm 0.01$ \\
\hline SBA [\%] & $81.6 \pm 2.4$ & $72.9 \pm 3.3$ \\
\hline SLA $[\mu \mathrm{g} / \mathrm{ml}]$ & $2.09 \pm 0.17$ & $1.82 \pm 0.11$ \\
\hline LPR [\%] & $82.8 \pm 3.7$ & $72.5 \pm 3.9$ \\
\hline Estradiol [pg/ml] & $44.7 \pm 3.4$ & $22.3 \pm 1.7^{* * *}$ \\
\hline $\begin{array}{l}\text { Progesterone } \\
{[\text { nmole/l] }}\end{array}$ & $1.54 \pm 0.07$ & $18.3 \pm 1.2^{* * *}$ \\
\hline Cortisol [nmole/l] & $132.7 \pm 10.5$ & $90.4 \pm 6.1^{\text {*** }}$ \\
\hline IFN $\gamma[\mathrm{pg} / \mathrm{ml}]$ & $176.4 \pm 15.7$ & $775.4 \pm 55.7^{* * *}$ \\
\hline IL-2 [pg/ml] & $33.1 \pm 1.6$ & $79.6 \pm 4.8^{* *}$ \\
\hline $\mathrm{TNF} \alpha[\mathrm{pg} / \mathrm{ml}]$ & $248.4 \pm 19.7$ & $489.7 \pm 28.4^{*}$ \\
\hline
\end{tabular}


To achieve the therapeutic effect, 1.71 intrauterine administration of primalact was required, which is 0.43 $(\mathrm{P}<0.05)$ less in comparison with metricur. After the treatment, $80.0 \%$ of the animals included in the experiment were fertilized, with a decrease in the period from the start of treatment on fertilization by 14.2 days $(\mathrm{P}<0.01)$ and decrease in the fertilization rate by 0.48 $(\mathrm{P}<0.05)$ compared to metricur usage as etiotropic agent.

Table 2. Therapeutic efficacy of a comprehensive method for the treatment of chronic endometritis in cows

\begin{tabular}{|c|c|c|}
\hline Indicators & First group & $\begin{array}{c}\text { Second } \\
\text { group }\end{array}$ \\
\hline Number of animals & 25 & 21 \\
\hline $\begin{array}{c}\text { Number of intrauterine } \\
\text { preparation } \\
\text { administrations }\end{array}$ & $1.71 \pm 0.12^{*}$ & $2.14 \pm 0.16$ \\
\hline Cured [cows] & 22 & 17 \\
\hline Therapeutic efficacy [\%] & 88.0 & 80.9 \\
\hline $\begin{array}{c}\text { Fertilized, from among } \\
\text { experimental animals [\%] }\end{array}$ & 80.0 & 66.7 \\
\hline Fertilization coefficient & $1.81 \pm 0.14^{*}$ & $2.29 \pm 0.18$ \\
\hline $\begin{array}{c}\text { Time from treatment start } \\
\text { to fertilization [days] }\end{array}$ & $34.7 \pm 2.81^{* *}$ & $48.9 \pm 3.19$ \\
\hline
\end{tabular}

Note: ${ }^{*}-\mathrm{P}<0.05 ;{ }^{* *}-\mathrm{P}<0.01 ;{ }^{* * *}-\mathrm{P}<0.001$

In the process of recovery after the treatment, the indicators of the immune-biochemical status of the cows normalize, while in animals of the first group, the changes are more pronounced (Table 3 ).

Indeed, in cows of the first group, recovery is accompanied by a decrease in the leukocyte content by $15.2 \%$, including eosinophils by $32.2 \%(\mathrm{P}<0.001)$, stab neutrophils by 1.65 times $(\mathrm{P}<0.001)$, monocytes by 2.24 times $(\mathrm{P}<0.001), \gamma$-globulin fraction of the protein by $30.1 \%$, with a simultaneous increase in segmented neutrophils and lymphocytes by 10.5 and $7.9 \%$, respectively, which indicates a decrease in the inflammatory response.

In addition, complex treatment with the use of aminosletone as a general stimulating agent and primalact as an antimicrobial is accompanied by an increase in the indicators of the general nonspecific resistance of the organism: bactericidal and lysozyme activity of blood serum by $34.9(\mathrm{P}<0.01)$ and $50.0 \%$ $(\mathrm{P}<0.02)$, respectively, the phagocytic activity of leukocytes by $13.4 \%(\mathrm{P}<0.05)$, and in animals of the second group by 13.8, 26.9 and $7.2 \%$, correspondingly. In the process of healing, the endogenous intoxication of the body of the cows of the first group decreases, which is manifested by a decrease in the activity of gammaglutamyltransferase by $26.3 \%$, the content of mediummolecular molecules by $18.8 \%$, malondialdehyde by $36.6 \%(\mathrm{P}<0.001)$ and the index of intoxication by $24.6 \%$, with an increase in the actioxidative activity of blood serum by $16.8 \%$, and in animals of the second group by $14.34 .5,14.4 \%, 7.5$ and $6.2 \%$, correspondingly. The recovery of cows of the first group is accompanied by a decrease in the functional load on the liver, as evidenced by a decrease in the activity of alkaline phosphatase by $31.6 \%(\mathrm{P}<0.05)$ and aspartate aminotransferase by $62.8 \%(\mathrm{P}<0.01)$, and in cows of the second group, respectively by $17.1 \%$ and $23.7 \%$.

Table 3. Indicators of immune-biochemical status of cows before and after chronic endometritis treatment

\begin{tabular}{|c|c|c|c|}
\hline \multirow[b]{2}{*}{ Indicators } & \multirow{2}{*}{$\begin{array}{c}\text { Before } \\
\text { treatment, } \\
\mathrm{n}=14\end{array}$} & \multicolumn{2}{|c|}{ After treatment } \\
\hline & & $\begin{array}{c}\text { First group, } \\
\mathrm{n}=7\end{array}$ & $\begin{array}{c}\text { Second } \\
\text { group, } n=7\end{array}$ \\
\hline Leukocytes [109/1] & $9.2 \pm 0.55$ & $7.8 \pm 0.33$ & $8.5 \pm 0.51$ \\
\hline Eosinophils [\%] & $8.7 \pm 0.44$ & $5.9 \pm 0.26^{* * *}$ & $8.1 \pm 0.33$ \\
\hline \multicolumn{4}{|l|}{ Neutrophils [\%] } \\
\hline stab & $3.3 \pm 0.12$ & $2.0 \pm 0.11^{* * * *}$ & $3.5 \pm 0.14$ \\
\hline segmented & $25.7 \pm 2.1$ & $28.4 \pm 1.5$ & $26.1 \pm 1.7$ \\
\hline Monocytes [\%] & $5.6 \pm 0.22$ & $2.5 \pm 0.17^{* * *}$ & $3.5 \pm 0.22^{* *}$ \\
\hline Lymphocytes [\%] & $56.7 \pm 4.4$ & $61.2 \pm 3.8$ & $58.8 \pm 4.3$ \\
\hline Total protein [g/l] & $85.3 \pm 4,5$ & $83.1 \pm 5.7$ & $82.9 \pm 5.0$ \\
\hline Albumins [\%] & $45.4 \pm 2.5$ & $51.6 \pm 3.8$ & $43.1 \pm 3.0$ \\
\hline$\gamma$-globulins [\%] & $9.3 \pm 0.64$ & $10.8 \pm 0.6$ & $10.0 \pm 0.8$ \\
\hline$\beta$-globulins [\%] & $19.8 \pm 1.3$ & $18.0 \pm 1.3$ & $20.7 \pm 1.9$ \\
\hline$\gamma$-globulins [\%] & $25.5 \pm 1.7$ & $19.6 \pm 1.2$ & $26.2 \pm 2.3$ \\
\hline GTP [units/l] & $19.2 \pm 1.7$ & $15.2 \pm 1.1$ & $16.8 \pm 1.5$ \\
\hline ALP [units/l] & $112.8 \pm 7.2$ & $85.7 \pm 4.1^{*}$ & $96.3 \pm 8.8$ \\
\hline AST [units/l] & $81.9 \pm 7.8$ & $50.3 \pm 4.2^{* *}$ & $66.2 \pm 5.2$ \\
\hline SBA [\%] & $58.6 \pm 4.5$ & $79.1 \pm 2.9^{* *}$ & $66.7 \pm 4.6$ \\
\hline SLA $[\mu \mathrm{g} / \mathrm{ml}]$ & $0.26 \pm 0.02$ & $0.39 \pm 0.02^{*}$ & $0.33 \pm 0.02$ \\
\hline LPR [\%] & $73.3 \pm 3.9$ & $83.1 \pm 3,6^{*}$ & $78.6 \pm 5.4$ \\
\hline $\begin{array}{l}\text { PI [cells/ } \\
\text { phagocyte] }\end{array}$ & $5.8 \pm 0.24$ & $7.5 \pm 0.31^{* * *}$ & $6.6 \pm 0.36$ \\
\hline $\begin{array}{l}\text { PN [cells/ } \\
\text { active phagocyte] }\end{array}$ & $7.9 \pm 0.44$ & $9.0 \pm 0.41^{*}$ & $8.4 \pm 0.51$ \\
\hline Carotene [mg \%] & $0.53 \pm 0.03$ & $0.65 \pm 0.03$ & $0.55 \pm 0.02$ \\
\hline Vitamin $\mathrm{A}[\mu \mathrm{M} / 1]$ & $2.04 \pm 0.18$ & $2.38 \pm 0.11^{*}$ & $2.18 \pm 0.16$ \\
\hline MMC [a.u.] $254 \mathrm{~nm}$ & $0.27 \pm 0.01$ & $0.23 \pm 0.02$ & $0.26 \pm 0.03$ \\
\hline $\mathrm{AOA}[\%]$ & $45.3 \pm 3.3$ & $52.9 \pm 3.7$ & $48.1 \pm 3,4$ \\
\hline $\mathrm{MDA}[\mu \mathrm{M} / \mathrm{L}]$ & $2.39 \pm 0.19$ & $1.75 \pm 0.13^{* * *}$ & $2.09 \pm 0.19$ \\
\hline Index of intoxication & $17.2 \pm 1.2$ & $13.8 \pm 0,8$ & $16.0 \pm 0.9$ \\
\hline
\end{tabular}

After the treatment, the degree of microbial contamination of the cervical-vaginal mucus decreased in the cows of the first group by 3.6 times (from $417.2 \pm 36.4$ to $115.2 \pm 10.5 \mathrm{CFU} / \mathrm{ml}$ ), and in animals the second only by 1.8 times (from $389.9 \pm 23.8$ to $212.2 \pm 16.4 \mathrm{CFU} / \mathrm{ml}$ ), which indicates incomplete rehabilitation of the uterine cavity.

Thus, chronic endometritis is diagnosed on average in $18.1 \%$ of infertile cows of the Central Federal District of the Russian Federation. The course of chronic endometritis in $48.7 \%$ of cases occurs against the background of ovarian hypofunction, in $11.0 \%$ of cases luteal cysts are diagnosed. With chronic endometritis, catarrhal-purulent, purulent-catarrhal exudate, echographically represented as single echopositive inclusions, is noted. The uterus has a pronounced cavity: $18.4 \pm 0.9 \mathrm{~mm}(11-35 \mathrm{~mm})$, the thickness of the uterine wall in chronic endometritis is on average $8.7 \pm 0.37 \mathrm{~mm}$. Morphometrically chronic endometritis is characterized by a decrease in the fraction of functionally active elements of the endometrium (integument epithelium, uterine glands, blood vessels) to $12.17 \%$. In the development of chronic endometritis, cows showed an increase in leukocyte content by $12.2 \%$ compared with clinically healthy animals, monocytes by 2.5 times, 
creatinine by $29.7 \%$, average molecular peptides by $25.0 \%$, and endogenous intoxication index by $25.4 \%$, circulating immune complexes by $38.5 \%$, with a decrease in bactericidal and lysozyme activity of blood serum by 10.7 and $12.9 \%$, respectively, and phagocytic activity of leukocytes by $12.4 \%$, indicating the presence of inflammatory phenomena, endogenous intoxication, tense functioning of excretory system against the background of decreasing indicators of general nonspecific resistance of the organism.

\section{Conclusion}

The effectiveness of the developed method for the treatment of chronic endometritis, involving the use of aminoseletone as a general stimulating agent and primalact as an etiotropic agent is $88.0 \%$. Recovery of animals after the treatment is accompanied by a decrease in the inflammatory response, endogenous intoxication, normalization of liver and kidneys, an increase in overall non-specific resistance and a decrease in uterine microbial contamination.

\section{References}

1. V.G. Gavrish, Thesis of Doctor of Sciences (Veterinary) (Saratov, 1997)

2. I.M. Sheldon, G.S. Lewis, S. LeBlanc, R.O. Gilbert, Theriogenology 65, 1516-1530 (2006)
3. A.M. Hussain, R.C.W. Daniel, D. O’Boyle, Theriogenology 34, 291-302 (1990)

4. I.M. Sheldon, S.B. Price, J. Cronin, R.O. Gilbert, J.E. Gadsby, Reprod. in Dom. Anim. 44, 1-9 (2009)

5. H. Zerbe, N. Schneider, W. Leibold, T. Wensing, T.A. Kruip, H.J. Schuberth, Theriogenology 54, 771-786 (2000)

6. J. Singh, R.D. Murray, G. Mshelia, Z. Woldehiwet, Review, Vet. J. 175, 301-309 (2008)

7. A.N. Turchenko, Veterinary 7, 33-38 (2001)

8. G.S. Lewis, Anim. Reprod. Sci. 82-83, 281-294 (2004)

9. M.J.W. Dohmen, J.A.C. Lohuis, G. Huszenicza et al., Theriogenology 43, 1379-1388 (1995)

10. S.J. LeBlanc, T.F. Duffield, K.E. Leslie, K.G. Bateman, G.P. Keefe, J.S. Walton, W.H. Johnson, J. of D. Sc. 85, 2223-2236 (2002)

11. G.G. Avtandilov, Medical morphometry (Meditsina, Moscow, 1990)

12. M.I. Retskiy, A.G. Shakhov, V.I. Shushlebin et al., Methodological recommendations on diagnostics, therapy and preventive measures in case of metabolic disorder in production animals (Voronezh, 2005)

13. A.G. Shakhov, Yu.N. Masyanov, M.I. Retskiy et al., Methodological recommendations on estimating and correcting of immune status of animals (Voronezh, 2005) 